\title{
The Burden of Childhood Atopic Dermatitis in the Primary Care Setting: A Report from the Meta-LARC Consortium
}

\author{
Jinan Al-naqeeb, MD, MPH, Sankirtana Danner, MA, CCRP, Lyle J. Fagnan, MD, \\ Katrina Ramsey, MPH, LeAnn Michaels, Julie Mitchell, Kelsey Branca, MPH, \\ Cynthia Morris, PhD, MPH, Donald E. Nease, Jr., MD, Linda Zittleman, MSPH, \\ Barcey Levy, MD, PhD, Jeanette Daly, RN, PhD, David Hahn, MD, MS, \\ Rowena J. Dolor, MD, MHS, Hywel C. Williams, DSc, FMedSci, \\ Joanne R. Chalmers, PhD, BSc, Jon Hanifin, MD, Susan Tofte, RN, FNP, \\ Katharine E. Zuckerman, MD, MPH, Karen Hansis, Mollie Gundersen, Julie Block, \\ Francie Karr, Sandra Dunbrasky, MD, Kathy Siebe, CPNP, Kristen Dillon, MD, \\ Ricardo Cibotti, PhD, Jodi Lapidus, PhD, and Eric L. Simpson, MD, MCR
}

Background: Little is known about the burden of atopic dermatitis (AD) encountered in US primary care practices and the frequency and type of skin care practices routinely used in children.

Objective: To estimate the prevalence of $\mathrm{AD}$ in children 0 to 5 years attending primary care practices in the United States and to describe routine skin care practices used in this population.

Design: A cross-sectional survey study of a convenience sample of children under the age of 5 attending primary care practices for any reason.

Setting: Ten primary care practices in 5 US states.

Results: Among 652 children attending primary care practices, the estimated prevalence of ever having AD was 24\% (95\% CI, 21-28) ranging from 15\% among those under the age of 1 to $38 \%$ among those aged 4 to 5 years. The prevalence of comorbid asthma was higher among AD participants compared to those with no AD, namely, $12 \%$ and $4 \%$, respectively $(P<.001)$. Moisturizers with high water: oil ratios were most commonly used (ie, lotions) in the non-AD population, whereas moisturizers with low water:oil content (ie, ointments) were most common when AD was present.

Conclusions: Our study found a large burden of AD in the primary care practice setting in the US. The majority of households reported skin care practices that may be detrimental to the skin barrier, such as frequent bathing and the routine use of moisturizers with high water: oil ratios. Clinical trials are needed to identify which skin care practices are optimal for reducing the significant burden of AD in the community. (J Am Board Fam Med 2019;32:191-200.)

Keywords: Atopic Dermatitis, Prevalence, Primary Health Care, Skin Care

Atopic dermatitis (AD) is a common chronic inflammatory skin condition that usually starts in early childhood but can develop at any age. ${ }^{1-3} \mathrm{AD}$ represents a substantial disability burden on a

This article was externally peer reviewed.

Submitted 6 August 2018; revised 14 November 2018; accepted 20 November 2018.

From Department of Dermatology, Oregon Health and Science University, Portland (JA, JH, ST, ELS); Oregon Rural Practice-based Research Network, Oregon Health and Science University, Portland (SD, LJF, LM, KB, KD); global scale. ${ }^{4}$ Large international studies reveal a wide range of prevalence rates in industrialized countries ranging between $10 \%$ to $30 \%$, with rates varying greatly by geographic area. ${ }^{5-7}$ US-specific

Public Health and Preventive Medicine, Oregon Health and Science University, Portland (KR, KEZ, JL); Oregon Clinical and Translational Research Institute, Oregon Health \& Science University, Portland (JM, CM); High Plains Research Network, University of Colorado, Denver (DEN, LZ); Iowa Research Network, University of Iowa, Iowa City (BL, JD); Wisconsin Research and Education Network, 
studies find similar high rates of disease prevalence and similar geographic variability in prevalence. ${ }^{8,9}$ Most of our understanding of AD prevalence in the United States stems from a limited number of national population-based surveys, which are now over 10 years old. ${ }^{2,8,9}$ Although they provide a reasonable estimate of population prevalence, population-based studies do not always accurately reflect the burden of a disease encountered in community health care settings-an important consideration for resource allocation by decision makers. ${ }^{10,11}$ A better understanding of the burden of $\mathrm{AD}$ and the associated allergic comorbidities encountered in primary care practices helps to plan disease prevention strategies appropriate to this setting. Prevention strategies that prevent AD development may also reduce allergic comorbidities that often follow $\mathrm{AD}$ development, such as allergic asthma.

Epidemiologic studies identify several risk factors for AD development, including climatic factors, ${ }^{12}$ cat ownership, ${ }^{13}$ proximity to traffic, ${ }^{14}$ early allergen sensitization, family history of atopic diseases, and an FLG gene mutation (a gene important for proper skin barrier function). ${ }^{15}$ In a large unselected cohort from the United Kingdom, skin barrier dysfunction as measured by transepidermal water loss at 2 days and 2 months of age was the strongest risk factor for $\mathrm{AD}$ development at 12

University of Wisconsin, Madison (DH); Primary Care Research Consortium, Duke University, Durham, North Carolina (RD); Centre of Evidence-Based Dermatology, University of Nottingham, England (HCW, JRC); Division of General Pediatrics, Oregon Health and Science University, Portland (KEZ); Patient Advocate (KH, MG); National Eczema Association, San Rafael, CA (JB); Mid-Columbia Medical Center, The Dalles, OR (FK); Treasure Valley Pediatric Clinic, Ontario (SD); Winding Waters Clinic, Enterprise (KS); National Institute of Arthritis and Musculoskeletal and Skin Diseases, National Institute of Health, Bethesda, MD (RC).

Funding: This study was supported by grant $1 \mathrm{U} 34$ AR065739-02 from the National Institute of Arthritis and Musculoskeletal and skin diseases (NIAMS) (Dr. Simpson) and partially supported by grant from Oregon Clinical and Translational Research Institute (OCTRI) grant number UL1TR000128. The funder has no role in the design and conduct of the study, collection, management, analysis, and interpretation of the data, preparation review, or approval of the manuscript, and the decision to submit the manuscript for publication.

Conflict of interest: none declared.

Corresponding author: Eric Simpson, MD, MCR, OHSU Department of Dermatology, 3303 SW Bond Avenue, CHH 16D, Portland OR 97239, Phone: 503-494-2121 (E-mail: simpsone@ohsu.edu) months of age, more so than an FLG mutation or family history of atopy. ${ }^{15}$

Because of the role early skin barrier dysfunction may play in $\mathrm{AD}$ development, our group and others have been interested in how skin care practices and moisturizer use may modify $\mathrm{AD}$ disease risk. Currently, there are no data to support the need for routine emollient use in healthy newborns. ${ }^{16}$ However, 3 pilot trials suggest daily moisturizer therapy in high-risk populations may reduce the risk of developing $\mathrm{AD}$ by as much as $50 \% .{ }^{17-19}$ The optimal type of moisturizer that protects against $\mathrm{AD}$ in not clear, although moisturizers with higher oil content are thought to enhance skin barrier function more so than lower oil content moisturizers. ${ }^{20}$ Because plain water and fragrances can be an irritant to skin, fragranced moisturizers with high water content may, in theory, be detrimental to skin barrier function. Some authors postulate that the increased use of fragranced lotions early in life may explain the rising epidemic of $\mathrm{AD}$, although no studies have shown this association in a rigorous manner. ${ }^{21}$

To develop and study novel skin care interventions as a prevention strategy for $\mathrm{AD}$, data are needed regarding the routine skin practices currently used by US families. In preparation for a large community-based trial evaluating moisturizers for the prevention of $\mathrm{AD}$, we sought to determine the prevalence of $\mathrm{AD}$ in children attending primary care settings by using a convenience sample of children under the age of 5 and aimed to describe current skin care practices used by parents on their children both with and without $\mathrm{AD}$.

\section{Methods}

\section{Study Design, Population, and Setting}

This study, named the Community-Based Assessment of Skin Care, Allergies and Eczema (CASCADE) study, was a cross sectional survey study conducted in 5 US states. CASCADE was a planning study to determine the feasibility of conducting a large, 5-year, community-based pragmatic randomized controlled clinical trial to test the hypothesis that certain skin care practices can prevent or delay $\mathrm{AD}$ and allergic comorbidities. Study participants were dyads of parents or guardians and children 0 to 5 years old attending 1 of 10 community-based pediatric $(\mathrm{n}=6)$ and family medicine $(n=4)$ clinics located in Oregon, Wis- 
consin, Colorado, North Carolina, and Iowa. These clinics were all members of a practice-based research network (PBRN) within their respective state and were a mix of rural and suburban practices. All participating PBRNs collaborate via the Meta-network Learning and Research Center (MetaLARC) consortium, an administrative structure funded by the Agency for Health care Research and Quality encompassing almost 1,000 primary care practices and 7,000 clinicians (https://www.ohsu.edu/ $\mathrm{xd} /$ outreach/oregon-rural-practice-based-researchnetwork/meta-larc/index.cfm, accessed April, 2018). PBRNs serve as essential partners in translating academic research advances into real-world health improvements in the general ambulatory care population. $^{22}$ The study was approved by the institutional review board (IRB\#11116) of Oregon Health and Science University and recruited participants from April 2015 through January 2016.

Inclusion required being a parent or legal guardian, aged $\geq 18$ years, of a child between the ages of 0 and 5 years who was a current patient at the participating clinic; respondents also needed to be able to read and write in either English or Spanish. Potential respondents were excluded if unable to complete the questionnaire due to mental or cognitive capacity, if they or another of the child's parents had already completed the questionnaire (ascertained by self-report), or if the child had been born preterm at less than 25 weeks of pregnancy.

\section{Recruitment}

The Iowa PBRN recruited participants by mail only, whereas all other PRBNs used a combination of the following methods to capture as wide a sample as possible: in clinic while waiting for their appointments, mailed surveys, and electronic surveys via Research Electronic Data Capture (REDCap) hosted by Oregon Health and Science University. This flexibility in recruitment methods allowed for a minimal impact on clinic workflow that is critical to performing research in this setting. Clinic staff were instructed to broadly distribute the surveys to all eligible patients attending the clinic during the enrollment period, without selecting for any demographic or medical history to minimize selection bias. Due to the nature of the survey distribution in a busy practice setting, refusals were not recorded; thus, we are unable to report a participation rate.

\section{Instrument}

The questionnaire was completed by the child's caregiver and included questions about $\mathrm{AD}$ history, symptoms, age of onset, presence of other atopic disorders, medications use, and skin care and bathing practices (Supplemental Figure 1.) The questionnaire was adapted from previous childhood AD surveys that have been used and validated in a community setting to measure the prevalence of $\mathrm{AD} .^{2,9,23}$

\section{$A D$ and Severity Assessment}

A history of $\mathrm{AD}$ was determined by a positive response to the question "Have you ever been told by a health care provider that your child has eczema or atopic dermatitis?" A similar question has been shown to have adequate sensitivity and specificity to estimate the prevalence of $\mathrm{AD}$ in the United States. ${ }^{24-26} \mathrm{We}$ assessed the effect of $\mathrm{AD}$ on the child's sleep by asking how many nights in the past week the child's sleep had been disturbed because of a red rash or eczema. $\mathrm{AD}$ severity was assessed by asking respondents to rate the rash or eczema as mild, moderate, or severe. This question has been used previously in epidemiologic studies to assess severity and found to be a good indicator of childhood AD burden. ${ }^{2,9,27}$

\section{Comorbidities and Family History}

A history of asthma and wheezing were measured using the questions "Has your child ever been diagnosed with asthma by a health care provider?" and "Has your child ever had wheezing?" Food allergies were measured by asking "Has your child ever been diagnosed with a food allergy by a health care provider?" Family history of any atopic condition was assessed by asking the question "Has at least 1 of your child's parents or older brothers or sisters (related by blood) ever had any of the following conditions: eczema, asthma, or hay fever/ spring-time allergies?" Parental history of asthma was considered positive if at least 1 of the parents had asthma. The questions were adapted from previously validated questions used in epidemiologic studies which measured comorbidities. ${ }^{28,29}$

\section{Skin Care and Bathing}

Moisturizer use was assessed by answering the question "do you use a moisturizer/lotion/ oil on your child's skin?" An affirmative response to the above question was followed by secondary ques- 
tions about the type of moisturizer and the application site-all over the body or just on dry areas. Moisturizer type was assessed by asking the following question: "Which moisturizer(s) did you use on your child?" The answer choices included the most commonly used commercial moisturizers brands: CeraVe cream, Cetaphil cream, Vaseline/petroleum jelly, Sunflower seed oil, Aveeno, Aquaphor, Vanicream, and Johnson's baby lotion. If the moisturizer that had been used was not listed in the answer choices that were given, the parents were instructed to check "other" and write what they were using. For a better understanding of current trends in moisturizer use, more than 1 answer was acceptable for this question. We stratified moisturizers based on their content: lotion, cream, ointment, or liquid oil. If the parents did not specify the type (ie, lotion, ointment, cream, or liquid oil), and the brand product could represent more than 1 type of moisturizer, the answer was excluded from analysis.

Moisturizer frequency and bathing or shower frequency was measured using the following questions: "Over the past 3 months, on average how many days per week was a moisturizer/ lotion/oil applied to your child's skin" and "Over the past 3 months, on average how many days per week did your child receive either a bath or shower?" Moisturizer frequency was asked only in those participants who were using moisturizers, whereas bathing frequency was asked of the whole sample. We categorized frequency of moisturizer use and bathing into 2 categories: $<4$ and 4 days or more per week. Because the biological effect of most moisturizers lasts more than 24 hours, we considered 4 days a week or more to be frequent use.

\section{Sample Size and Statistical Analysis}

A sample size of approximately 250 was estimated to provide a reasonably precise sample of disease prevalence from age 0 to 5 years with a $95 \%$ CI within 5 percentage points. Our actual sample was significantly larger to obtain an adequate sample from all age groups and study sites. We excluded 9 respondents who failed to provide the child's age $(\mathrm{n}=5)$ and history of provider diagnosis of $\mathrm{AD}$ $(\mathrm{n}=3)$, or both $(\mathrm{n}=1)$; our final dataset included 652 children.

We calculated simple descriptive statistics overall and for $\mathrm{AD}$ and non-AD groups and tested differences with $\chi^{2}$ tests. To estimate age-specific characteristics of $\mathrm{AD}$, we used predictive margins from a logistic regression model with clustered standard errors to account for correlation between respondents from the same clinic. Similarly, estimates of comorbid conditions and skin care practices resulted from logistic or log-binomial (relative risk) models with clustered standard errors and including age, in months, as a covariate to adjust for this effect. All analyses were performed using Stata SE for windows version 14 (Stata Corp, College Station, Texas).

\section{Results}

A total of 652 caregivers with children aged between 0 to 5 years participated in the study with 24\% (95\% CI, 21-28) overall parent-reported prevalence of $\mathrm{AD}$. The mean \pm standard deviation of age of participants was $22.5 \pm 19.4$ months, and the mean age at which $\mathrm{AD}$ first appeared was $9 \pm$ 10.4 months. Those with AD were far more likely to experience dry skin than those in the non-AD group ( $63 \%$ vs $17 \%, P<.001)$. There were no significant differences between those with $\mathrm{AD}$ compared with the non-AD group in regard to sex, parent language, race/ethnicity, or geographic distribution. Participants' characteristics are summarized in Table 1.

\section{AD Prevalence and severity}

As expected, $\mathrm{AD}$ prevalence steadily increased with age, ranging from $14.5 \%$ among children less than 1 year old to $38 \%$ among children 4 to 5 years old $(P<.001)$. Overall, $58 \%$ of children with AD had mild symptoms, $39 \%$ had moderate, and only $3 \%$ (4 children) had severe disease. Among the same children with $\mathrm{AD}, 21 \%$ had reported $\mathrm{AD}$-related sleep disturbance in the previous week. Although we did not detect trends in severity or AD- related sleep disturbance by age, prescriptions for eczema medications were common overall $(75 \%$ of children with $\mathrm{AD}$ ) and increased with age. A total of $67 \%$ and $69 \%$ of children less than 1 year of age and 1 to 2 year olds, respectively, were prescribed medication compared to higher percents, $75 \%$ and $86 \%$, for older age groups ( 2 to 3 years, and 4 to 5 years, respectively; $P=.019$ ); see Table 2 .

\section{Comorbidities and Family History}

Children with $\mathrm{AD}$ in this study had a higher reported prevalence of certain comorbidities with 
Table 1. Population Characteristics by Atopic Dermatitis Status

\begin{tabular}{|c|c|c|c|c|}
\hline & Overall & $\mathrm{AD}$ & No AD & \\
\hline Characteristic & No. (\%) & No. (\%) & No. (\%) & $P$ value* \\
\hline $\mathrm{N}$ & $652(100)$ & $159(100)$ & $493(100)$ & \\
\hline Child age (years) & & & & $<.001$ \\
\hline$<1$ & $240(37)$ & $35(22)$ & $205(42)$ & \\
\hline 1 & $165(25)$ & $39(25)$ & $126(26)$ & \\
\hline 2 & $75(12)$ & $21(13)$ & $54(11)$ & \\
\hline 3 & $55(8)$ & $19(12)$ & $36(7)$ & \\
\hline 4 & $65(10)$ & $26(16)$ & $39(8)$ & \\
\hline $5^{+}$ & $52(8)$ & $19(12)$ & $33(7)$ & \\
\hline Child sex: Female & $321(50)$ & $73(46)$ & $248(51)$ & .35 \\
\hline Caregiver responded in Spanish & $32(5)$ & $8(5)$ & $24(5)$ & .93 \\
\hline Race/ethnicity & & & & .53 \\
\hline Hispanic, any race & $140(21)$ & $30(19)$ & $110(22)$ & \\
\hline White non-Hispanic & $367(56)$ & $91(57)$ & $276(56)$ & \\
\hline Black non-Hispanic & $75(12)$ & $24(15)$ & $51(10)$ & \\
\hline Asian non-Hispanic & $11(2)$ & $2(1)$ & $9(2)$ & \\
\hline More than one race & $34(5)$ & $6(4)$ & $28(6)$ & \\
\hline Prefer not to say & $25(4)$ & $6(4)$ & $19(4)$ & \\
\hline Generally dry skin & $181(28)$ & $99(63)$ & $82(17)$ & $<.001$ \\
\hline State & & & & 0.25 \\
\hline Oregon & $212(33)$ & $46(29)$ & $166(34)$ & \\
\hline Wisconsin & $78(12)$ & $21(13)$ & $57(12)$ & \\
\hline Iowa & $93(14)$ & $29(18)$ & $64(13)$ & \\
\hline Colorado & $56(9)$ & $17(11)$ & $39(8)$ & \\
\hline North Carolina & $213(33)$ & $46(29)$ & $167(34)$ & \\
\hline
\end{tabular}

$\mathrm{AD}$, atopic dermatitis; $\mathrm{N}$, total no. of children.

*p value from $\chi^{2}$ tests.

${ }^{\dagger}$ Includes children 72 months (6 years, 0 months) of age.

known or suspected links to AD. Age adjusted prevalence of asthma was about 3 times as high in the $\mathrm{AD}$ group compared to the non-AD group (prevalence ratio $[\mathrm{PR}], 3.0 ; P<.001)$. History of wheezing, including wheezing without a cold, were higher among the $\mathrm{AD}$ population compared to the non-AD group (PR, 1.4 and $1.8 ; P<.05$ ). Food allergies were 3.7 times more common among those with $\operatorname{AD}(P=.005)$. Family history of any atopic condition — a known risk factor for $\mathrm{AD}$ - was also significantly higher in the $\mathrm{AD}$ group (PR, 1.3; $P<.001)$. (Table 3)

\section{Skin Care and Bathing}

Use of moisturizer (at any frequency) was common in the whole sample; however, it was found to be significantly higher among the $\mathrm{AD}$ group (90\%) compared to the non-AD group $(74 \%, P<.001)$. For children without $\mathrm{AD}$, parents most commonly used lotions $(64 \%)$ on their children, whereas par- ents of children with established $\mathrm{AD}$ most commonly used oil-rich moisturizers, such as cream or ointment $(65 \%)$ possibly in response to guidelinedriven recommendations for $\mathrm{AD}$ treatment by their health practitioners (Table 4). The mean number of days used per week for the overall sample was 4.3 and the mean number of daily bath/showers per week was 4.6. Among those who used moisturizer, the majority (65\%) applied it 4 or more days per week and there was no significant difference in moisturizer frequency application when stratified by age (Table 5). Those with $\mathrm{AD}$ applied moisturizers more days per week than those in the non-AD group ( 4 or more days a week $=75 \%$ vs $60 \%, P=$ $.001)$. Overall, $41 \%$ of the children received a bath/ shower less than 4 days/week, whereas 59\% received a bath/shower 4 or more days per week. There was no significant difference in bathing frequency between those with $\mathrm{AD}$ compared to those without $\mathrm{AD}$. When bathing frequency was examined 
Table 2. Atopic Dermatitis Prevalence and Severity and Medication Prescribed, by Age*

\begin{tabular}{|c|c|c|c|c|c|c|}
\hline \multirow[b]{2}{*}{ Age Category } & \multirow[b]{2}{*}{$\mathrm{N}$} & \multirow[b]{2}{*}{$\begin{array}{l}\% \text { Prevalence of } \\
\operatorname{AD}^{\dagger}(95 \% \mathrm{CI})\end{array}$} & \multicolumn{4}{|c|}{ Among children with AD: } \\
\hline & & & $\mathrm{N}$ & $\begin{array}{c}\text { Moderate/severe }{ }^{\ddagger} \mathrm{AD} \\
\text { Percent }(95 \% \mathrm{CI})\end{array}$ & $\begin{array}{l}\text { Sleep disturbed in past } \\
\text { week Percent }(95 \% \mathrm{CI})\end{array}$ & $\begin{array}{l}\text { Medication prescribed } \\
\text { Percent }(95 \% \mathrm{CI})\end{array}$ \\
\hline Overall & 652 & $24(21-28)$ & 159 & $42(36-47)$ & $21(15-27)$ & $75(68-82)$ \\
\hline $\begin{array}{l}\text { Child age } \\
<1 \text { year }\end{array}$ & 240 & $15(12-17)$ & 35 & $48(37-60)$ & $24(11-37)$ & $67(54-79)$ \\
\hline 1 year & 165 & $24(19-29)$ & 39 & $29(13-44)$ & $15(5-24)$ & $69(56-82)$ \\
\hline 2 to 3 Years & 130 & $31(22-40)$ & 40 & $41(28-53)$ & $22(6-39)$ & $75(60-90)$ \\
\hline $\begin{array}{l}4 \text { to } 5^{\S} \\
\text { Years }\end{array}$ & 117 & $38(29-48)$ & 45 & $49(31-66)$ & $22(14-31)$ & $86(76-97)$ \\
\hline $\mathrm{p}$ value & & $<.001$ & & .094 & .69 & .019 \\
\hline
\end{tabular}

$\mathrm{AD}$, atopic dermatitis; $\mathrm{CI}$, confidential interval.

*Percents are mean predictions from a logistic model with clustered standard errors to account for correlation between children from the same clinic. $\mathrm{P}$ values are from likelihood ratio $\chi^{2}$ test.

${ }^{\dagger}$ Represents ever history of $\mathrm{AD}$.

${ }^{\ddagger}<3 \%$ reported severe rash overall.

${ }^{\S}$ Includes children age 6 years, 0 months.

by age, those who were under the age of 1 received less baths/showers per week compared to the older participants regardless of $\mathrm{AD}$ status $(P<.001)$. Summaries of skin care practices seem in Tables 4 and 5 .

\section{Discussion}

We estimated the prevalence of $\mathrm{AD}$ among children age 0 to 5 attending community-based primary care practices to be approximately $24 \%$, with a mean age of $\mathrm{AD}$ onset in the first year of life. Parents reported that $\mathrm{AD}$ severity was mild in more than half of participating children, and 20\% of those with $\mathrm{AD}$ had their sleep disturbed at least once a week as a result of their $\mathrm{AD}$. As anticipated, a higher prevalence of $\mathrm{AD}$-associated comorbidities and a family history of atopic conditions were found among those with $\mathrm{AD}$. The majority of par- ents were using some kind of moisturizer on their child's skin on a regular basis; children with $\mathrm{AD}$ were more likely to receive creamy and oily moisturizers, whereas children without $\mathrm{AD}$ were receiving lotions primarily. This large community-based study is the first study to describe the pediatric $\mathrm{AD}$ burden within community-based primary care practices and provides important insight into skin care practices that may be modifiable in future disease prevention studies.

A higher prevalence of $\mathrm{AD}(24 \%)$ was found in children under the age of 5 in our study compared to US population-based studies using data from the National Survey of Children Health. Shaw et al. ${ }^{8}$ found prevalence rates ranging between $13.12 \%$ and $14.73 \%$ among those under the age of 4 . Similar to our findings, previous studies of chronic

Table 3. History of Atopy and Allergic Comorbidities by Atopic Dermatitis Status*

\begin{tabular}{|c|c|c|c|c|c|c|c|c|c|}
\hline \multirow[b]{2}{*}{ Comorbidity } & \multicolumn{2}{|c|}{$\begin{array}{c}\text { Overall } \\
(\mathrm{n}=652)\end{array}$} & \multicolumn{2}{|c|}{$\begin{array}{c}\mathrm{AD} \\
(\mathrm{n}=159)\end{array}$} & \multicolumn{2}{|c|}{$\begin{array}{l}\text { No AD } \\
(\mathrm{n}=493)\end{array}$} & \multicolumn{2}{|c|}{$\begin{array}{c}\text { Age-Adjusted } \\
\text { Prevalence Ratio }\end{array}$} & \multirow[b]{2}{*}{$P$ value } \\
\hline & $\%$ & $95 \% \mathrm{CI}$ & $\%$ & $95 \% \mathrm{CI}$ & $\%$ & $95 \% \mathrm{CI}$ & $\mathrm{PR}^{\mathrm{a}}$ & $95 \% \mathrm{CI}$ & \\
\hline Asthma & 7 & $(5-8)$ & 12 & $(9-16)$ & 4 & $(3-6)$ & 3.0 & $(1.8-4.9)$ & $<.001$ \\
\hline Wheezing without cold & 6 & $(4-9)$ & 9 & $(6-13)$ & 5 & $(3-8)$ & 1.8 & $(1.1-2.7)$ & .011 \\
\hline Wheezing (ever) & 21 & $(18-23)$ & 26 & $(19-33)$ & 19 & $(16-22)$ & 1.4 & $(1.02-1.9)$ & .038 \\
\hline Food allergy & 4 & $(3-5)$ & 8 & $(4-12)$ & 2 & $(1-3)$ & 3.7 & $(1.5-9.2)$ & .005 \\
\hline Family history of atopic condition & 69 & $(63-75)$ & 82 & $(74-90)$ & 65 & $(59-71)$ & 1.3 & $(1.2-1.4)$ & $<.001$ \\
\hline Parent with asthma & 31 & $(25-37)$ & 36 & $(28-44)$ & 29 & $(24-35)$ & 1.2 & $(1.01-1.5)$ & .037 \\
\hline
\end{tabular}

$\mathrm{AD}$, atopic dermatitis; $\mathrm{CI}$, confidential interval; PR, prevalence ratio.

*Percents are marginal predictions and prevalence ratio is the exponentiated coefficient from a log-binomial (relative risk) model for the comorbidity including $\mathrm{AD}$ and age (months) as predictors. $P$ values are from the Wald test for $\mathrm{AD}$ vs no $\mathrm{AD}$. 
Table 4. Skin Care Practices by Atopic Dermatitis Status*

\begin{tabular}{|c|c|c|c|c|c|c|c|}
\hline \multirow[b]{2}{*}{ Skin Care Practice } & \multicolumn{2}{|c|}{ Overall } & \multicolumn{2}{|c|}{$\mathrm{AD}$} & \multicolumn{2}{|c|}{ No AD } & \multirow[b]{2}{*}{$P$ value } \\
\hline & $\%$ & $(95 \% \mathrm{CI})$ & $\%$ & $(95 \% \mathrm{CI})$ & $\%$ & $(95 \% \mathrm{CI})$ & \\
\hline $\mathrm{N}$ & \multicolumn{2}{|c|}{652} & \multicolumn{2}{|c|}{159} & \multicolumn{2}{|c|}{493} & \\
\hline Any current moisturizer use (\%) & 78 & $(71-84)$ & 90 & $(84-96)$ & 74 & $(66-82)$ & $<.001$ \\
\hline Among current moisturizer users $(\mathrm{N})$ & \multicolumn{2}{|c|}{500} & \multicolumn{2}{|c|}{144} & \multicolumn{2}{|c|}{356} & \\
\hline \multicolumn{8}{|l|}{ Where moisturizer applied } \\
\hline All over body & 91 & $(88-94)$ & 88 & $(81-94)$ & 93 & $(90-95)$ & .30 \\
\hline Just to dry, flaky, or red spots & 9 & $(6-12)$ & 13 & $(6-19)$ & 7 & $(5-10)$ & \\
\hline \multicolumn{8}{|l|}{ Type of moisturizer(s) used ${ }^{\dagger}$} \\
\hline Lotion & 54 & $(47-61)$ & 29 & $(18-40)$ & 64 & $(58-70)$ & $<.001$ \\
\hline Ointment & 28 & $(20-35)$ & 41 & $(33-49)$ & 22 & $(13-31)$ & $<.001$ \\
\hline Cream & 14 & $(8-19)$ & 24 & $(17-32)$ & 9 & $(4-14)$ & $<.001$ \\
\hline Liquid Oil & 4 & $(3-6)$ & 7 & $(3-11)$ & 3 & $(2-5)$ & .05 \\
\hline Unspecified lotion or cream & 32 & $(28-36)$ & 38 & $(29-47)$ & 29 & $(25-33)$ & .022 \\
\hline
\end{tabular}

$\mathrm{AD}$, atopic dermatitis; $\mathrm{CI}$, confidential interval.

*Percents are mean predictions from a logistic model with age (months) and clustered standard errors to account for correlation between babies from the same clinic. $P$ values are from Wald test for AD vs no AD adjusted for age.

${ }^{\dagger}$ Multiple answers possible to type of moisturizer.

illnesses found a higher prevalence rate in the primary care setting than in the population setting. ${ }^{10,11}$ Measuring the prevalence of $\mathrm{AD}$ in children attending primary care clinics reflects the disease burden in these community clinics, whereas population-based studies provide esti- mates for a general population that may or may not be accessing the health care system. ${ }^{10} \mathrm{Un}$ derstanding the disease burden is important from both perspectives to provide information to investigators, clinicians, patients, and resource allocation stakeholders.

Table 5. Proportions of patients reporting frequent ( $>4$ days per week) bathing and moisturizer by age and Atopic Dermatitis Status*

\begin{tabular}{|c|c|c|c|c|c|c|c|c|c|}
\hline \multirow[b]{2}{*}{$\begin{array}{l}\text { Child } \\
\text { age }\end{array}$} & \multicolumn{3}{|c|}{ Overall } & \multicolumn{3}{|c|}{$\mathrm{AD}$} & \multicolumn{3}{|c|}{ No AD } \\
\hline & $\mathrm{N}$ & $\%^{\dagger}$ & $(95 \% \mathrm{CI})$ & $\mathrm{N}$ & $\%^{+}$ & $(95 \% \mathrm{CI})$ & $\mathrm{N}$ & $\%^{+}$ & $(95 \% \mathrm{CI})$ \\
\hline \multicolumn{10}{|c|}{ Frequent bathing ( $\geq 4$ days per week) } \\
\hline$<1$ & 224 & 45 & $(36-53)$ & 33 & 36 & $(15-58)$ & 191 & 46 & $(39-53)$ \\
\hline 1 & 158 & 70 & $(63-78)$ & 38 & 63 & $(52-74)$ & 120 & 72 & $(64-81)$ \\
\hline 2 to 3 & 124 & 69 & $(57-82)$ & 37 & 68 & $(43-92)$ & 87 & 70 & $(58-82)$ \\
\hline 4 to $5^{\ddagger}$ & 111 & 63 & $(51-76)$ & 44 & 61 & $(41-82)$ & 67 & 64 & $(47-81)$ \\
\hline Total & 617 & 59 & $(52-67)$ & 152 & 58 & $(47-69)$ & 465 & 60 & $(52-68)$ \\
\hline \multicolumn{10}{|c|}{ Frequent moisturizer use ${ }^{\ddagger}$ ( $\geq 4$ days per week) } \\
\hline$<1$ & 173 & 60 & $(53-67)$ & 30 & 77 & $(67-87)$ & 143 & 57 & $(50-64)$ \\
\hline 1 & 132 & 71 & $(62-67)$ & 35 & 74 & $(67-82)$ & 97 & 70 & $(59-81)$ \\
\hline 2 to 3 & 95 & 69 & $(57-82)$ & 33 & 79 & $(70-88)$ & 62 & 65 & $(45-84)$ \\
\hline 4 to $5^{\S}$ & 77 & 61 & $(47-75)$ & 41 & 71 & $(60-82)$ & 36 & 50 & $(31-69)$ \\
\hline Total & 477 & 65 & $(57-73)$ & 139 & 75 & $(69-81)$ & 338 & 61 & $(52-70)$ \\
\hline
\end{tabular}

$\mathrm{AD}$, atopic dermatitis; CI, confidential interval.

*Percents are mean predictions from a logistic model with clustered standard errors to account for correlation between babies from the same clinic.

${ }^{\dagger}$ Total $\mathrm{N}$ (denominator) for given age/AD group.

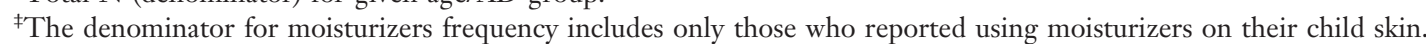

${ }^{\$}$ Includes children aged 6 years, 0 months. 
Similar to population-based studies, our study confirmed that allergic comorbidities are also common in children with $\mathrm{AD}$ attending communitybased primary care clinics. The consistency of our data with other national surveys of allergic diseases lends support that our sample population adequately represents the US AD population. For example, the overall prevalence of asthma found in our sample population of 0 to 5 year olds of $7 \%$ closely mirrors the Centers for Disease Control and Prevention statistics from the Behavioral Risk factor Surveillance System 2013 data, which measured the lifetime prevalence of asthma in the general US population to be $7.3 \%$ among children under the age of $5 .{ }^{30} \mathrm{We}$ also confirmed the higher rate of asthma among those with $\mathrm{AD}(16 \%)$ compared to non-AD children (4\%) consistent with many previous studies. ${ }^{31-33}$ Patients with $\mathrm{AD}$ also had a higher prevalence of a family history of allergic disease in our study, confirming that a family history of atopy represents an important risk factor for $\mathrm{AD}$ development.

This study provides insight into skin care practices used in the very young-a subject of relatively limited study, especially given our new understanding of the importance of the skin barrier in the development of $\mathrm{AD}$. Kelleher and colleagues ${ }^{15}$ found skin barrier function in the first 2 months of life to be the strongest predictors of $\mathrm{AD}$ development. Thus, skin care practices that have the potential to alter skin barrier function may represent important determinants or modifiers of $\mathrm{AD}$ development. In this study, the majority of caregivers applied some kind of moisturizer on their child's skin, even among children without reported $\mathrm{AD}$ diagnosed by a health care provider. As expected, children with $\mathrm{AD}$ reported more frequent use of thick moisturizers (ie, creams and ointments) than those without $\mathrm{AD}$, as this is the most common first-line treatment for mild $\mathrm{AD}$. Thus, children with $\mathrm{AD}$ seem to receive appropriate education regarding moisturizer use supported by published treatment guidelines. ${ }^{34}$ In those without $\mathrm{AD}$, we found the majority of parents used more water-based moisturizers (ie, lotions) on the skin, as opposed to thicker moisturizers, with the majority of usage more than 4 days per week. These skin care practices are similar to those described in a single-center study in Oregon and confirm findings from a market-based study showing a very high use of water-based moisturizers (lotions) in babies on a regular basis. ${ }^{35,36}$ This high use of moisturizers is likely a result of cultural preferences or marketing, as skin care guidelines for neonates do not recommend a routine use of moisturizers. The US Association of Women's Health, Obstetric and Neonatal Nurses (AWHONN) released updated guidelines for neonate and infant skin care that state it is unclear whether the routine use of moisturizers benefits infant health. ${ }^{16}$ Certain moisturizers could potentially even harm the skin barrier with frequent use, such as those with irritants, fragrances, or high water content, ${ }^{37-40}$ thus potentially provoking $\mathrm{AD}$ in genetically susceptible neonates. There is no clinical evidence, however, that the use of fragranced lotions in neonates promotes $\mathrm{AD}$. The guidelines do recommend moisturizer use for dry or cracking skin and routine use for $\mathrm{AD}$ and infantile seborrheic dermatitis. Published guidelines from a European roundtable meeting on best practice for infants recommend routine moisturizer/moisturized cleanser use during and after bathing for infants who are at high risk of developing $\mathrm{AD}$ if it is needed based on their skin condition. ${ }^{41}$ It is unclear what influence the frequency and type of moisturizer used has on the development of $\mathrm{AD}$. Further studies are needed to inform best practices in the general population.

Similar to moisturizer use, the type and frequency of bathing is an understudied area in newborn health. Several studies found that exposure to water alone can be detrimental to the skin barrier, ${ }^{42}$ although no studies have evaluated the clinical effects of various methods of bathing or frequency on $\mathrm{AD}$ development. We found that more than half of the participants received baths/showers on 4 or more days per week. These results are in agreement with a previous case-control study that found the mean frequency of baths children received was 4 to 5 per week. ${ }^{36}$ The current AWHONN guidelines for neonates and infants recommended bathing infants every few days and no more than every other day. ${ }^{16}$ In addition, AWHONN concluded that there were no clear benefits from daily bathing; however, they left the decision about frequency of bathing to be based on individual neonate's needs considering the family beliefs and culture. ${ }^{16}$ Similar recommendations were published in 2009 by the European roundtable meeting on best practice for infants that recommend bathing 2 to 3 times a week by using a mild cleanser and concluded that bathing does not harm the baby. ${ }^{41}$

The strengths of our study include the use of primary care-based sampling to better understand 
$\mathrm{AD}$ burden in the primary care clinical setting, the use of clinics that are members of PBRNs experienced in executing research protocols, and the inclusion of questions regarding skin care practices that are usually overlooked in $\mathrm{AD}$ surveys. Limitations of the study are that we cannot exclude the potential for selection bias that could yield artificially inflated prevalence rates. Because of regional variation in $\mathrm{AD}$ prevalence, the prevalence data from the states included in this study may not be generalizable to all states in the United States. In addition, the diagnosis of $\mathrm{AD}$ was made by parental report of a health care provider diagnosis rather than direct examination by a provider. Last, a possible failure to complete the survey existed for children with more complex health care visits, such as those with chronic health conditions.

In conclusion, our study found a large burden of $\mathrm{AD}$ in the primary care practice setting in the United States. The majority of households use skincare practices that may be detrimental to the skin barrier of children not diagnosed with $\mathrm{AD}$, such as frequent bathing and the use of watery lotions frequently. Clinical trials will allow us to identify which skin care practices are optimal for reducing the significant burden of $\mathrm{AD}$ in the community.

The authors thank the families who donated their time to participate, the participating clinicians, and the following research assistants who helped collect and manage data-Chou Xiong, Erica Suarez, Danielle Smith, and Annette Vu.

To see this article online, please go to: http://jabfm.org/content/ 32/2/191.full.

\section{References}

1. Williams HC. Clinical practice. Atopic dermatitis. N Engl J Med 2005;352:2314-24.

2. Hanifin JM, Reed ML. A population-based survey of eczema prevalence in the United States. Dermatitis 2007;18:82-91.

3. Weidinger S, Novak N. Atopic dermatitis. Lancet 2016;387:1109-22.

4. Hay RJ, Johns NE, Williams HC, et al. The global burden of skin disease in 2010: an analysis of the prevalence and impact of skin conditions. J Invest Dermatol 2014;134:1527-34.

5. Odhiambo JA, Williams HC, Clayton TO, Robertson CF, Asher MI. Global variations in prevalence of eczema symptoms in children from ISAAC Phase Three. J. Allergy Clin Immunol 2009;124:12518.e1223.

6. Worldwide variation in prevalence of symptoms of asthma, allergic rhinoconjunctivitis, and atopic ec- zema: ISAAC. The International Study of Asthma and Allergies in Childhood (ISAAC) Steering Committee. Lancet. 1998;351:1225-32.

7. Deckers IA, McLean S, Linssen S, Mommers M, van Schayck CP, Sheikh A. Investigating international time trends in the incidence and prevalence of atopic eczema 1990-2010: a systematic review of epidemiological studies. PLoS One 2012;7:e39803.

8. Shaw TE, Currie GP, Koudelka CW, Simpson EL. Eczema prevalence in the United States: data from the 2003 National Survey of Children's Health. J Invest Dermatol 2011;131:67-73.

9. Silverberg JI, Simpson EL. Associations of childhood eczema severity: a US population-based study. Dermatitis 2014;25:107-14.

10. Mokraoui NM, Haggerty J, Almirall J, Fortin M. Prevalence of self-reported multimorbidity in the general population and in primary care practices: a cross-sectional study. BMC Res Notes 9:314, 2016.

11. Fortin M, Hudon C, Haggerty J, van den Akker M, Almirall J. Prevalence estimates of multimorbidity: a comparative study of two sources. BMC Health Serv Res 2010;10:111.

12. Silverberg JI, Hanifin J, Simpson EL. Climatic factors are associated with childhood eczema prevalence in the United States. J Invest Dermatol 2013;133: 1752-9.

13. Bisgaard H, Simpson A, Palmer CN, et al. Geneenvironment interaction in the onset of eczema in infancy: filaggrin loss-of-function mutations enhanced by neonatal cat exposure. PLoS Med 2008; 5:e131.

14. Lu C, Deng L, Ou C, Yuan H, Chen X, Deng Q. Preconceptional and perinatal exposure to trafficrelated air pollution and eczema in preschool children. J Dermatol Sci 2017;85:85-95.

15. Kelleher M, Dunn-Galvin A, Hourihane JO, et al. Skin barrier dysfunction measured by transepidermal water loss at 2 days and 2 months predates and predicts atopic dermatitis at 1 year. J Allergy Clin Immunol 2015;135:930-5.e931.

16. New neonatal skin care evidence-based practice guideline. Nursing for Women's Health. 2013;17: 545-6.

17. Horimukai K, Morita K, Narita M, et al. Application of moisturizer to neonates prevents development of atopic dermatitis. J Allergy Clin Immunol 2014;134: 824-30.e826.

18. Simpson EL, Chalmers JR, Hanifin JM, et al. Emollient enhancement of the skin barrier from birth offers effective atopic dermatitis prevention. J Allergy Clin Immunol 2014;134:818-23.

19. Lowe AJ, Su JC, Allen KJ, et al. A randomized trial of a barrier lipid replacement strategy for the prevention of atopic dermatitis and allergic sensitization: the PEBBLES pilot study. Br J Dermatol 2018; 178:e19-e21. 
20. Caussin J, Groenink HW, de Graaff AM, et al. Lipophilic and hydrophilic moisturizers show different actions on human skin as revealed by cryo scanning electron microscopy. Exp Dermatol 2007;16:891-8.

21. Cork MJ, Robinson D, Vasilopoulos Y, et al. Predisposition to sensitive skin and atopic eczema. Community Pract 2005;78:440-2.

22. Westfall JM, Mold J, Fagnan L. Practice-based research-"Blue Highways" on the NIH roadmap. JAMA 2007;297:403-6.

23. von Kobyletzki LB, Berner A, Carlstedt F, Hasselgren M, Bornehag CG, Svensson A. Validation of a parental questionnaire to identify atopic dermatitis in a population-based sample of children up to 2 years of age. Dermatology 2013;226:222-6.

24. Silverberg JI, Patel N, Immaneni S, et al. Assessment of atopic dermatitis using self-report and caregiver report: a multicentre validation study. Br J Dermatol 2015;173:1400-4.

25. Garg NK, Silverberg JI. Eczema is associated with osteoporosis and fractures in adults: a US population-based study. J Allergy Clin Immunol 2015;135: 1085-7.e1082.

26. Laughter D, Istvan JA, Tofte SJ, Hanifin JM. The prevalence of atopic dermatitis in Oregon schoolchildren. J Am Acad Dermatol 2000;43:649-55.

27. Pustisek N, Vurnek Zivkovic M, Situm M. Quality of life in families with children with atopic dermatitis. Pediatr Dermatol 2016;33:28-32.

28. Draaisma E, Garcia-Marcos L, Mallol J, Sole D, Perez-Fernandez V, Brand PL. A multinational study to compare prevalence of atopic dermatitis in the first year of life. Pediatr Allergy Immunol 2015; 26:359-66.

29. Schultz Larsen F, Diepgen T, Svensson A. The occurrence of atopic dermatitis in north Europe: an international questionnaire study. J Am Acad Dermatol 1996;34:760-764.

30. Centers for Disease Control and Prevention. Data, statistics, and surveillance. Asthma surveillance data. Available from: http://www.cdc.gov/asthma/ asthmadata.htm. Published 2016.

31. Ziyab AH, Karmaus W, Zhang H, et al. Association of filaggrin variants with asthma and rhinitis: is eczema or allergic sensitization status an effect modifier? Int Arch Allergy Immunol 2014;164:308-18.
32. von Kobyletzki LB, Bornehag CG, Hasselgren M, Larsson M, Lindstrom CB, Svensson A. Eczema in early childhood is strongly associated with the development of asthma and rhinitis in a prospective cohort. BMC Dermatol 12:11, 2012.

33. Hoppin JA, Jaramillo R, Salo P, Sandler DP, London SJ, Zeldin DC. Questionnaire predictors of atopy in a US population sample: findings from the National Health and Nutrition Examination Survey, 2005-2006. Am J Epidemiol 2011;173:544-52.

34. Eichenfield LF, Tom WL, Berger TG, et al. Guidelines of care for the management of atopic dermatitis: section 2. Management and treatment of atopic dermatitis with topical therapies. J Am Acad Dermatol 2014;71:116-32.

35. Gao X, Simpson EL. Market trends in baby skin care products and implications for clinical practice. Pediatr Dermatol 2014;31:734-8.

36. Rendell ME, Baig-Lewis SF, Berry TM, et al. Do early skin care practices alter the risk of atopic dermatitis? A case-control study. Pediatr Dermatol 2011;28:593-5.

37. Kiec-Swicrczynska M, Chomiczewska-Skora D, Swierczynska-Machura D, Krecisz B. [Impact of wet work on epidermal barrier (tewl and stratum corneum hydration) and skin viscoelasticity in nurses]. Med Pr 2014;65:609-19.

38. Danby SG, AlEnezi T, Sultan A, et al. Effect of olive and sunflower seed oil on the adult skin barrier: implications for neonatal skin care. Pediatr Dermatol 2013;30:42-50.

39. Tsang M, Guy RH. Effect of aqueous cream BP on human stratum corneum in vivo. $\mathrm{Br} \mathrm{J}$ Dermatol 2010;163:954-8.

40. Danby SG, Al-Enezi T, Sultan A, Chittock J, Kennedy K, Cork MJ. The effect of aqueous cream BP on the skin barrier in volunteers with a previous history of atopic dermatitis. Br J Dermatol 2011;165: 329-34.

41. Blume-Peytavi U, Cork MJ, Faergemann J, Szczapa J, Vanaclocha F, Gelmetti C. Bathing and cleansing in newborns from day 1 to first year of life: recommendations from a European round table meeting. J Eur Acad Dermatol Venereol 2009;23:751-9.

42. Tsai TF, Maibach HI. How irritant is water? An overview. Contact Dermatitis 1999;41:311-4. 